\title{
ONLY A MATTER OF TIME? THE ROLE OF CRIMINAL COMPETENCE IN AVOIDING ARREST**
}

\author{
FRÉDÉRIC OUELLET ${ }^{\mathrm{a}} \&$ MARTIN BOUCHARD ${ }^{\mathrm{b}}$ \\ a School of Criminology, Université de Montréal, Montréal, QC, Canada \\ ${ }^{\mathrm{b}}$ School of Criminology, Simon Fraser University, Burnaby, BC, Canada \\ **The two authors contributed equally to the paper, reverse alphabetical order was used.
}

Forthcoming in Justice Quarterly

July 2016

Link to article: http://dx.doi.org/10.1080/07418825.2016.1219761

Corresponding author: Frédéric Ouellet,

Email: frederic.ouellet.1@umontreal.ca

C.P. 6128, succursale Centre-ville

Montréal QC Canada

H3C 3J7

Telephone: (514) 343-1376

FAX: (514) 343-2269

Acknowledgements. We wish to thank the anonymous reviewers for the useful comments and suggestions made throughout the publication process. 


\title{
Only a matter of time? The role of criminal competence in avoiding arrest
}

\begin{abstract}
While prior research has shown that the probability of detection plays a role in the decision-making of many offenders, much less is known on offenders' relative success in avoiding arrest. In this study, we draw from detailed criminal career data on 172 offenders involved in lucrative criminal activities to examine the role of criminal competence in the probability of being arrested in a given month. We examine a particular aspect of competence, criminal efficiency, which is defined as the ability to earn a relatively large amount of money for each crime committed. Our research design allows us to disentangle the effect of criminal efficiency as a static trait of offenders from the dynamic variations in efficiency that offenders experience over time. Results show that efficiency is a strong, negative predictor of arrest, both at the static and dynamic levels.
\end{abstract}

Key words: arrest, criminal competence, criminal efficiency, exposure time, criminal careers, life history calendars. 


\section{Introduction}

There is a wide variation in the frequency of arrests over the course of criminal careers (Blumstein, Cohen, Piquero, Visher, 2010; Farrington et al., 2003; Piquero et al., 2001; Wiesner, Capaldi \& Kim, 2007). Although crime specific or situational predictors of risks can sometimes be found to matter (e.g. Bouchard \& Nguyen, 2010; Lussier, Bouchard \& Beauregard, 2011), extant research on the individual probabilities of being arrested suggests at least two general hypotheses that may explain the occurrence of this event. The first is the exposure hypothesis, where the more crimes committed by an offender, the higher the likelihood of being arrested. In this deterministic scenario, offenders have little control over their destiny. The longer they are criminally active, the greater the risks of detection. The exposure hypothesis does take into account the fact that some types of crime are riskier than others (e.g. auto theft versus robbery) (Blumstein, Cohen, Roth \& Visher, 1986; Blumstein et al., 2010) but, in this perspective, it is only a matter of time before the inevitable happens.

The second assumption that can be derived from the literature on variations in probabilities of detection is that arrested offenders are failed offenders. We label this idea as the competence hypothesis. Critics of studies conducted in prison, for example, are quick to note that these samples are made of failed offenders (Jacobs \& Wright, 2006; Wright \& Decker, 1997; p. 4). In other words, skilled offenders get away with it, while the less gifted ones find themselves in prison. If we accept this premise, offenders would then have some control over their destiny. All else equal, variations in risks of being arrested would be a function of variations in detection avoidance skills, or competence.

Gaps in the literature on variations in the risks of being arrested limit our assessment of these two hypotheses. First, arrest risks it is typically used as a measure of recidivism where risks are assumed to be static, and predicted mainly by individual offender characteristics (Huebner, 
Varano \& Bynum, 2007; Lattimore, Visher \& Linster, 1995). While informative in its own right, this approach neglects intervening circumstances (dynamic factors) that come with involvement in and out of crime (Lussier \& Davies, 2011). Few studies have examined arrest risks by drawing from a life course perspective in order to disentangle how both stable attributes and dynamic life circumstances influence the probabilities of being arrested. Second, many detection or recidivism studies are based solely on official data. Doing so overlooks the true risks incurred by offenders for each undetected crimes they have committed (Lussier \& Mathesius, 2012; Paternoster \& Piquero, 1995; Stafford \& Warr, 1993). Third, the notion of "competence" in offending is sometimes used in criminological research (Bouchard \& Nguyen, 2011; Brezina \& Topalli, 2012; Loughran, Nguyen, Piquero \& Fagan, 2013; Steffensmeier \& Ulmer, 2005; Sutherland, 1937; Tremblay, 2010; Tremblay \& Morselli, 2000; Wright \& Decker, 1994), but rarely is it actually measured in a way where variations in competence can be examined systematically, as an attribute of offenders.

Using a retrospective self-report inmate survey which drew from the life course calendar strategy, the current study fills these gaps in the literature by examining changes in the risks of being arrested as a function of 1) criminal exposure ("fatality"), and 2) criminal competence ("efficiency"). Our modeling strategy allows for our measures of exposure and competence to be tested for their potential static effects (e.g. are generally more competent offenders less likely to be arrested?), as well as their dynamic effects (e.g. are the months in which offenders display higher levels of competence associated with a higher likelihood of being arrested?).

In addition, we believe this inquiry is important for at least two more reasons. First, while studies in the deterrence research tradition does consider experiences of impunity as having a major role in how offenders assess their likelihood of getting caught (Paternoster \& Piquero, 1995; Stafford \& Warr, 1993), including experiential effects where participation in crime 
decreases perceptions of risks (Nagin, 1998; Saltzman, Paternoster, Waldo \& Chiricos, 1982), it does not typically consider variations in offenders' ability to directly impact their own impunity levels through the way they do crime. The more offenders attribute their detection avoidance to their own actions (i.e. internal attribution bias), the more motivation to continue to hone their criminal skills. Second, on a more practical level, still relatively few risk assessment studies take into account the variations in costs and benefits incurred by offenders in assessing the likelihood of future offending. This is so despite the growing evidence of the power of experiences with both impunity and monetary rewards in offender decision-making, including the likelihood of desistance (Anwar \& Loughran, 2011; Loughran, Paternoster, Piquero, \& Fagan, 2012; Shover \& Thompson, 1992). Offenders do not tend to leave a good thing behind- whether or not their selfassessment is accurate.

\section{Criminal Exposure and Arrest Risks}

Exposure is central in understanding actual or perceived risk of arrest incurred by offenders when they are active in crime. It has been defined as the amount of time an individual is not incapacitated, and thus free to commit crimes (Piquero et al., 2001). The exposure hypothesis is used in this study in a slightly different way, to refer to the volume of, and nature of criminal activities committed by individual offenders. The larger the volume of crimes committed, the riskier the activities, the more offenders are exposing themselves to arrest. The exposure hypothesis is meant to capture a necessary set of controls to investigations of arrest risks (Blumstein et al., 2010; Piquero et al., 2001). Many ethnographic studies have shown that a nontrivial proportion of offenders consider the threat of legal sanctions in these terms ${ }^{1}$. Studies conducted in prison (Shover, 1996), as well as work conducted with offenders who had never

\footnotetext{
${ }^{1}$ Others think they can beat the odds stacked against them. This is the essence of the competence hypothesis, as shall be seen below.
} 
been incarcerated (Wright \& Decker, 1994; 1997) all suggest that offenders adopt a sort of fatalistic attitude toward the threat of legal sanctions; they perceive that there is a great deal of (bad) luck in the evaluation of these risks ${ }^{2}$. In this perspective, the arrest event becomes largely dependent on the parameters that define criminal involvement: individual arrest risks are proportional to the degree of exposure to which an offender is submitted.

Very few empirical studies have tested the exposure hypothesis explicitly. This is particularly surprising considering that exposure time is essential to understand criminal behavior within criminal careers (Blumstein et al., 2010; Piquero et al., 2001). This can be explained largely by difficulties surrounding the operationalization of the concept, at least as defined in this study. First, measuring exposure time and arrest risks require specific data on criminal involvement and contacts with the criminal justice system at multiple time points in time, data that are not always available (Ouellet, Boivin, Leclerc \& Morselli, 2013). Second, offenders do not commit crimes at all times throughout their criminal careers. Voluntarily or not, criminal careers undergo temporary interruptions at various times, and for different reasons - not simply because of incarceration (Glaser, 1969; Laub \& Sampson, 2003; Nagin \& Land, 1993; Piquero, 2004). Crime opportunities and suitable co-offenders may not always be available (Tremblay, 1993), or offenders may be sick or hospitalized, invest strictly in legitimate ventures, etc. Controlling for periods of criminal inactivity is essential, but remains a methodological challenge since repeated measures of criminal involvement outside of incarceration periods need to be factored in statistical models. Most studies that have considered exposure time control only for episodes of incarceration, but they assume that offenders are criminally active at all times outside of these periods (Horney, Osgood \& Marshall, 1995; McGloin, Sullivan, Piquero \& Pratt, 2007;

\footnotetext{
${ }^{2}$ In fact, offenders seem to be much more influenced by the rewards from crime(Piliavin et al., 1986; Piquero, Paternoster, Pogarsky, \& Loughran, 2011). It would perhaps be more accurate to consider the consideration of costs and benefits as a sequence - the notion of costs may have played a role prior to making the decision to commit crimes, but its influence diminishes relative to rewards once that decision has been made.
} 
Piquero et al., 2001). Controlling for other periods of inactivity is important because these periods are often a concrete way in which offenders help reduce their likelihood of being arrested, without such decision needing to be labeled as a particular "skill" they have.

Third, to grasp the full degree of exposure to arrest risks, it is important to measure the intensity of criminal activity, and not simply whether offenders are "active". In principle, each crime committed can be detected by authorities and each crime increases relative exposure to arrest. Our argument is meant to capture cumulative risk over a given time period. In other words, the exposure hypothesis does not imply that the arrest risk per crime also increases with each additional crime committed. In fact, Blumstein et al. (2010) estimated that arrest risk per crime and offense frequency had a reverse relationship: the more crimes committed, the lower the risk per crime. Yet, the cumulative risk has the reverse function, as high frequency offenders get arrested more often given their high volume of criminal activity ${ }^{3}$. Controlling for the intensity of criminal involvement requires that researchers collect monthly self-reported crime data. Of the few studies that did rely on such designs to examine exposure to legal consequences, Horney and Marshall (1991) emphasized that frequency of crimes varies considerably over time, while Horney et al. (1995) showed that life circumstances largely explain these variations. Temporal variations in criminal intensity must be taken into account as a key predictor in studies on arrest risks.

Finally, it has been demonstrated that the nature of the crime committed affect the probability of being arrested (Blumstein et al., 1986; Blumstein et al., 2010). In that sense, the exposure hypothesis has to take into account the fact that some types of crime are riskier than others. Violent crimes in general and robbery in particular, have been shown to increase the

\footnotetext{
${ }^{3}$ Using middle values for the ranges in offense frequency provided in table 5 in Blumstein et al (2010, p. 542), projecting these values over a year of activity, we can estimate an annual arrest rate of .35 to .66 for the low frequency assault offenders, .62 to .85 for the medium frequency categories, and 3.5 to 3.84 arrests/year for the high frequency assault offenders. This general pattern holds for other categories of crimes (robbery and burglary) as well.
} 
likelihood of arrest (Blumstein et al., 1986; Blumstein et al., 2010). Other types of crimes, like drug offenses, expose offenders to a different pattern of detection, first because there is rarely a victim involved, and second because of the nature of the risks involved. Each drug selling transaction is subject to a trivial risk of arrest (Caulkins \& MacCoun, 2003), so much so that Blumstein et al.'s (1986) seminal study of arrest risks preferred not to provide specific estimates for drug crimes in the main text. At the same time, the small pay-off per transaction at the retail level creates incentives for increasing the volume of transactions per month, creating additional exposure to detection. In this study, we explicitly account for the different dynamics involved in market versus predatory crimes in modeling exposure to arrest.

\section{Competence and Arrest Risks}

The second central hypothesis of this study examines more closely the role of competence in avoiding arrests. Competence in crime remains an understudied area in criminal career research, and there is no real empirically validated measure of the concept (see Loughran, et al., 2013, for a review). Offenders' perceptions about their own competence may provide indirect information on actual skills (Brezina \& Topalli, 2012), but it would not constitute a suitable measure to test the competence hypothesis, especially in light of recent research findings on some of the biases of self-assessment (Loughran et al., 2012). The research on offender selfassessments of competence is important for our purposes, however, for two reasons. First, such research highlights that not all offenders are unconcerned by the threat of legal sanctions. In fact, many think they 1) can play a direct role in avoiding arrest, and 2) have the skills to do so. Second, how offenders assess themselves is a predictor of arrest risks. A recent study by Loughran et al. (2012) on the notion of "overconfidence" on two samples of young offenders is particularly revealing. The more overconfident offenders were, the more likely they were to be 
arrested. Specifically, offenders who believed that their own risks of arrest were low compared to other offenders were more likely to be arrested. Thinking that one's own risks were high, in other words, acted as a sort of protective factor.

Ideally, a measure of competence would not be self-assessed, but reflect something relatively objective about the way in which offenders do crime. It would be able to differentiate the skilled offenders from the unskilled, the professionals from the amateurs (Steffensmeier \& Ulmer, 2005; Sutherland, 1937). It would tap into the way offenders commit their crimes, their ability to execute, their efficiency compared to their counterparts. It would be scalable and comparable across offenders involved in a variety of crimes. Some research on active offenders has tapped into the sort of skills or "expertise" distinguishing successful burglars from nonoffenders (Wright, Logie \& Decker, 1995), professional thieves from other thieves (Sutherland, 1937), or the variety of skills necessary to be a successful entrepreneur in the fencing business (Steffensmeier \& Ulmer, 2005). These in-depth interviews may be better suited to capture the subtleties of offender skills and efficiency than large survey study samples. Yet, an important goal of scholars who are focused on notions of skills, criminal capital, and criminal achievement is to uncover indicators most likely to capture the essence of competence in a larger survey context.

Because competence is likely to be a predictor of success in crime, criminal achievement researchers have been the most concerned with the concept and its measurement. McCarthy and Hagan (2001) examined the literature on achievement in legitimate contexts to find key predictors that could also potentially explain who gets ahead in crime. Guided by Clausen's (1991) concept of non-task specific competence, McCarthy and Hagan (2001) framed competence as a term encompassing a range of general attributes such as "intellectual capacity, dependability, and self-confidence of efficacy" (p. 1040). They operationalized competence in 
non-criminal terms, using a 7-item attitudinal scale that attempts to capture Clausen's general concept. Attitudinal competence was not found to be a direct predictor of income, but was found to intensify the effect of social and human capital on income. While their work has greatly advanced research on the role of competence in criminal outcomes, it has not provided us with a behavioral measure of competence that could capture criminal competence.

Research on criminal human capital adopted measures of criminal experience and specialization to capture the counterpart to human capital (Bouchard \& Nguyen, 2010; Loughran et al., 2013; McCarthy \& Hagan, 2001; Nguyen \& Bouchard, 2013; Nguyen et al., 2016). These measures could theoretically be considered as proxies for competence; but in the end, we side with achievement scholars in keeping competence and criminal human capital as conceptually and empirically distinct. What these proxies of criminal human capital and attitudinal measures of competence miss, we argue, is a way to differentiate offenders on the efficiency with which they commit their crimes. In the original study establishing some of the groundwork for research on criminal achievement, Tremblay and Morselli (2000) proposed a measure of criminal efficiency that potentially solves some of the limitations of other measures. The authors merged criminal earnings with offending frequency to create a measure of pay-off per crime, or criminal efficiency. This measure of criminal efficiency is adopted in the current study as an indicator of criminal competence. Each offense and each illegal transaction represents a moment in time and space where offenders make themselves vulnerable to detection, or for something to go wrong. All else equal, offenders who make the highest pay-off per crime have invested less of this "timeat-risk", for a higher pay-off. Efficiency is typically considered as a ratio of time and effort relative to an outcome. Although it would be reasonable to expect offenders who receive high pay-off for their crimes to have lower ratios of time invested-to-rewards, this measure (time invested) is not available to us. We can only consider the crimes themselves and their associated 
outcomes (the pay-off). In other words, we consider each crime as the concrete "investment" made by offenders toward the reception of a monetary reward. A benefit of the measure is that it is not necessarily static: offenders may go through fluctuations in criminal efficiency over time, depending on their ability to find attractive targets ${ }^{4}$. In turn, these variations may influence the amount of risks they are willing to take (a slow month may lead to more risks taken), and their ability to avoid arrest (the more risks they take, the higher the odds of being arrested).

\section{The Current Study}

In this paper, we propose a dynamic analysis of risks of arrest that tests two hypotheses that were found to be associated with detection in prior literature. First, we test the exposure hypothesis where the duration of criminal activity, and monthly variations in the amount of crimes committed by an offender are expected to directly influence the risks of being arrested. Second, we test the criminal competence hypothesis where monthly variations in criminal efficiency demonstrated by offenders are expected to directly impact their risks of being arrested. We do so in the context of an inmate survey that focuses specifically on lucrative criminal activities, and where all offenders in the sample were eventually arrested, though not all at the same rate. Was the timing of the arrest simply a function of exposure, of where the most skilled offenders able to delay the inevitable?

\section{Data and Methods}

The data used in this study are based on interviews conducted between 2000 and 2001 with 262 federal inmates (all males) from 5 penitentiary institutions located in the area of

\footnotetext{
${ }^{4}$ Although this does not apply directly to our study, a potential downside of the measure is its overlap with illegal earnings, an outcome measure often used in criminal achievement research. In our view, efficiency is an important dimension of the general concept of competence, but only one of them. More direct measures of criminal process, of "criminal skills in action", would complement the efficiency dimension tackled in this study.
} 
Montreal (essentially in medium and minimum security level penitentiary). Respondents were randomly chosen from a population list of inmates who were serving time for sentences that began shortly before the interview (76 percent had been incarcerated for less than 2 years at the time of the interview). A few inmates could not be interviewed for various reasons, but 80 percent of those invited accepted to participate. Face-to-face interviews with inmates were chosen as the preferred approach in order to increase the reliability of the answers, especially for the more complex questions associated with the timing of life events, and of the criminal network ${ }^{5}$. The survey collected information on different aspects of inmates' lives likely to impact criminal careers, such as criminal and legal activities, legal and illegal earnings, crime frequency and cooffending patterns, arrests, and incarceration periods.

The survey was oriented towards lucrative forms of crime. Respondents were given a list of property and market crimes and asked which ones they had been involved in, in the 36 months preceding their current incarceration. Then, for each type of crime reported by respondents, follow up questions asked the months for which they were active in that crime, the number of crimes committed in the window period, the average personal pay-off per crime, and whether they had co-offenders. Note that the starting point of the window period is the last month of freedom before the current incarceration. Data were collected retrospectively for each of the previous 35 months before this last month of freedom. The life history calendar strategy (LHC) was used to facilitate reports of activities (legal as well as illegal) and life events on a monthly basis.

Although 262 criminals were interviewed, the sample used in this study is composed of 172 inmates. There were three exclusion criteria. First, inmates were excluded on the basis of missing data in the LHC $(n=23)$. Second, given our interest in pay-offs per crime, we excluded

\footnotetext{
${ }^{5}$ For more details on the interview procedures see Morselli and Tremblay (2004).
} 
inmates who did not report any lucrative criminal activity during the window period $(n=45)$.

Finally, inmates who were active in crime less than three months during the same period $(\mathrm{n}=22)$

had to be removed because we could not calculate valid measures describing their criminal involvement prior to incarceration ${ }^{6}$. To study patterns of change in an outcome across multiple time points, measurements must be taken a minimum of three times. This dataset has been analyzed before (e.g. Bouchard \& Ouellet, 2011; Charest, 2004; Morselli \& Tremblay, 2004; Morselli, Tremblay \& McCarthy, 2006). However, none of these studies made use the life history calendar component of the research design, nor did they make use of the longitudinal data describing the monthly variations in criminal activity.

The Life history calendar method (LHC) developed by Freedman, Thornton, Camburn, Alwin, and Young-DeMarco (1988) was implemented in criminology for the study of criminal careers, and proved to be reliable (Griffin \& Armstrong, 2003; Horney \& Marshall, 1991; Horney et al., 1995; McGloin et al., 2007; Sutton, Bellair, Kowalski, Light \& Hutcherson, 2011; Uggen \& Thompson 2003). The LHC used in this study allowed us to precisely locate, on a monthly basis, for each inmate : 1) months spent in prison/penitentiary, probation, on parole or in halfway houses; 2) months during which they were arrested; 3) city of residence; 4) life events (hospitalization, divorce, birth of a child, mortality of a significant other, job loss); 5) conventional life circumstances (details on their work status and their legitimate earnings (jobs or social welfare, living with a girlfriend); 6) nature and context of criminal involvement (type of crime involved in, crime lambda, illegal earnings). Recall of criminal activities is facilitated once the inmates visualize the other elements included in the calendars (Roberts, Mulvey, Horney,

\footnotetext{
${ }^{6}$ Differences in means tests were conducted to evaluate the extent of the differences between included and excluded individuals. Of all variables incorporated in the analyses, only low self-control, number of criminal contacts and payoff per crime were found to significantly differ; excluded offenders had higher levels of self-control ( $p<.01)$, fewer numbers of criminal contacts $(\mathrm{p}<.05)$ and lower mean pay-off per crime $(\mathrm{p}<.01)$ compared to included offenders. Our sample could be described as biased toward offenders who are committed to earning money from crime.
} 
Lewis \& Arter, 2005). In particular, Morris and Slocum (2010) assessed the validity of LHC measures of self-reported arrests over a three-year period using a sample of incarcerated women. They focused specifically on the evaluation of data from the Life history method, using the timing of arrests as a benchmark. Although the correspondence between the official data and unofficial data was not perfect, the authors concluded that the LHC method is a valid approach for eliciting accurate retrospective data on the prevalence and frequency of arrests.

Arrest

This study is interested in changes in the risks of being arrested for individual offenders. Every month in which offenders are criminally active is coded for the presence or absence of an arrest. To be at risk of being arrested, offenders need to be both 1) criminally active ${ }^{7}$, and 2) free to commit crimes. It follows that months spent in prison/penitentiary and months where no criminal inactivity is registered are excluded from analysis. Nearly two thirds of offenders in our sample were incarcerated at least once during the window period. The average length of these episodes of incarceration was 10 months. Our analysis focuses on all months during which offenders were criminally active during the window period (172 offenders X 13.8 active street months on average per offender). The majority of offenders in our sample (83.7\%) experienced at least one arrest during the window period (excluding the arrest that led to current incarceration). On average, offenders were arrested 1.6 times over the 36-month window period. The arrest occurred, on average, after 12.5 months of criminal activity.

\section{Dynamic Predictors}

\footnotetext{
${ }^{7}$ Offenders can be criminally active, but not obtain any monetary gains from their crimes (e.g. failed, attempted, aborted crimes). These months are rare (3\% of the months included in this study), but they are incorporated in the analysis because they fit our two main criteria.
} 


\section{Exposure}

Three indicators measure the degree of exposure to which offenders were subjected during the window period. The first takes into account the duration of criminal activity. The longer the criminally active period, the greater the likelihood of being arrested. Accordingly, to measure the cumulative effect of time, each criminally active month is numbered, and considered to be part of a sequence. On average, each offender was active for 13.8 months $^{8}$. The second indicator measures the intensity of criminal activity. Intensity is measured by the frequency of crimes committed each month. Respondents reported an average of 30.59 crimes per month ${ }^{9}$. Finally, the third indicator accounts for the fact that risks can be impacted by the type of activity in which offenders are involved. More specifically, our third indicator captures the differential exposure associated with involvement in market crimes compared to other crimes. Because pure violent criminals were excluded, we grouped criminal activities in two categories, crimes against property (e.g. robbery, burglary, auto theft, theft, fraud, swindles, etc.) and market crimes (e.g. drug dealing and distribution, contraband, loan sharking, sex-related markets, fencing of stolen goods, etc.). Market crimes often involve continuity, and often a large number of small transactions compared to predatory offenses. Market crimes typically do not involve victims, which may have an impact on the risks of being arrested. Our measure reflects the proportion of market crimes committed by individuals, which we calculated by dividing the number of market

\footnotetext{
${ }^{8}$ It should be noted that $37.5 \%$ offenders were active during all months of freedom (still excluding months of incarceration). This means that nearly two out of three offending sequences have at least one period criminal inactivity). These intermittent trajectories are typically characterized by two distinct criminal sequences (mean $=1.8$ sequences). These crime sequences lasted a mean of 5 consecutive months in this sample.

${ }^{9}$ Note that the intensity of criminal activities and criminal efficiency were log-normally transformed prior to the multivariate analyses. This was the preferred strategy given the log-normal distribution of the original variables, the transformation of which produced normal distributions and helped us avoid violation of the normality assumption. Note that the median of original criminal intensity variable was 30 crimes per month, compared to the back transformed log natural mean of 30.59 per month for the logged variable used in the analyses. For criminal efficiency, the median of the original pay-off per crime is $171.42 \$$ compared to the back transformed log natural mean of $245.28 \$$ per crime for the logged variable used in the analyses.
} 
crimes by the total number of crimes for each month. On average, involvement in market crimes accounts for $68.9 \%$ of monthly criminal activities.

\section{Criminal Efficiency}

The second competing hypothesis in this research is that offenders are able to avoid or delay arrest through criminal competence. A measure of criminal efficiency is assumed to be the most proximal indicator of the competence in this sample. As in Tremblay and Morselli (2000), criminal efficiency is measured as the average pay-off per crime, calculated by dividing the total illegal earnings by the total number of crimes committed for each month in which offenders were active. For each type of crime, respondents were asked, "When active during the window period, how much (\$) would you make per crime/transaction?” The question was meant to include only gains they personally made, excluding any shares that co-offenders would have made (on the validity and reliability of self-reported criminal earnings gathered in this study see Charest, 2004; Morselli and Tremblay, 2010). Although we cannot be totally certain that all offenders have understood the pay-off question the same way, it was not a cause of ambiguity during data collection. Respondents reported on average a pay-off of $\$ 245$ per offense.

\section{Controls}

Our models also take into account the sources of formal (parole, probation or halfway house) and informal (legitimate work, intimate partner) social control on a monthly basis. A significant proportion of offenders reported involvement in legitimate work (61\%) during months of criminal activity. From a risk and reward points of view, months where criminal earnings are not the only source of income allow offenders more freedom to carefully choose the criminal opportunities that appear more interesting to them. The average proportion of months living with 
an intimate partner is $43 \%$. Offenders who are active under surveillance may be more at risk. In this sample, $38.4 \%$ of offenders had at least one month under surveillance. For those under surveillance, the mean length of supervision is 10 months.

Table 1 reports the proportion of offenders with at least one change for each type of life event during the window period (e.g., from being employed to unemployed or vice versa). Overall, 86.6 percent of offenders have experienced at least one transition, and over 78.5 percent have experienced two or more transitions during the window period. Horney et al. (1995) reported that $85 \%$ of their American sample experienced at least one change in their life circumstances over the same time period, with numbers that are very close for each category we have in common.

\section{Static Predictors}

We also control for between-individual differences on a number of characteristics assumed to be potentially associated with arrest risks: age at the beginning of the window period, high school education, age of onset, low self-control, daily alcohol user, hard drug use, size of criminal network, and presence of a criminal mentor. First, because of their experience, it is possible that older offenders are better at avoiding arrests. The average age at the beginning of the window period is 33 years. Age captures an effect of maturation (Hirschi \& Gottfredson, 1983) and it is possible that this effect helps understand the ability to avoid arrest. Education can be an asset in avoiding arrest. Few respondents have graduated from high school. We distinguish the respondents who have their high school diploma (18.6\%) of those who did not (81.6\%).

Offenders were on average 15.2 years old $(\mathrm{SD}=6.8)$ when they committed their first crime. It is well established that age of onset is a reliable predictor of the duration of the criminal career, but the role it plays in the risks of being arrested is unclear. Our low self-control measure 
takes into account a series of traits that may be associated with higher risks of being arrested. Respondents completed the Grasmick and colleagues (1993) low self-control scale (mean of 80.3 in this sample; a higher score means less self-control). It is expected that those offenders who are lacking self-control are possibly more inclined to take risks. Substance use is another control for risk taking behaviors. We included dichotomous measures to distinguish between participants who reported daily alcohol use, and hard drug users (monthly consumption of cocaine, heroin, crack, etc.). We include these measures as static predictors because substance use data was not collected using the LHC. We also control for the number of past incarcerations. On average, offenders in this sample have experienced 1.8 episodes of incarceration before the window period. It is conceivable that past failures allowed offenders to learn from their mistakes resulting in lower risks of being arrested. Alternatively, these episodes may have made them subject to increased surveillance by authorities, thus exposing them to greater risks.

Finally, we included two measures of the criminal social capital of participants. Criminal social capital can indirectly capture the number of criminal opportunities available to offenders, but also instruction or guidance resources that can facilitate criminal efficiency, or enhance offenders' ability to avoid arrest (Bouchard \& Nguyen, 2010; Bouchard \& Ouellet, 2011; Morselli et al., 2006). First, thinking of the entire study period, participants were asked to report the number of partners, suppliers, co-offenders, and other people relevant to their criminal activities. We used this question to measure the size of the criminal network. Participants had an average of seven partners in their core criminal network ${ }^{10}$. In the same section, participants were also asked to identify the presence of a mentor in crime. Nearly $42 \%$ of offenders identified the presence of such a person in their criminal network, which had been shown to predict variations

\footnotetext{
${ }^{10}$ The consumption of alcohol or drugs and the number of partners tend to vary over time. Because we don't have this information on a monthly basis, we are forced to use static measures; this is a limitation of our study.
} 
in criminal earnings (Morselli et al., 2006) and escalation in drug market offending (Ouellet, Bouchard, and Malm, 2016).

[Table 1 about here]

\section{Modeling Strategy}

Our analysis is based on time-period (months) at level 1 clustered into offenders at level 2. Generalized linear mixed (GLM) models are used to test the two main hypotheses of this study. GLM models are used to identify the antecedent factors (static factors) and intervening factors (dynamic factors or life circumstances) that have a direct effect on the probability of being arrested in a given month. The logic behind GLM is similar to logistic regression; we seek to model the occurrence of an event - arrest in this case. These models allow for the incorporation of both dynamic factors (level 1) and static factors (level 2) simultaneously; to examine intraindividual changes in life circumstances as well as differences between offenders. This type of multilevel models fits well with repeated measures data (Van Der Leeden, 1998). Data on individuals taken at regular intervals were structured hierarchically: months of criminal activity are nested within individuals. Our GLM models take the context around arrests into account, which varies from one individual to another, sometimes from one arrest to the other for the same individual, in order to examine the correlates of the arrest event for the months in which offenders were criminally active ${ }^{11}$. The flexibility inherent in GLM allows us to fully take into account the fact that offenders do not have the same number of months under observation during the window period, and to systematically remove from consideration months of incarceration or criminal inactivity.

\footnotetext{
${ }^{11}$ As observed in the LHC data, arrests generally occurred close to the crime, making the 30-day period we have for each month suitably long enough to incorporate changes in behavior and the arrest event itself. It is also important to clarify that the modeling strategy only allows to highlight associations between independent variables and the outcome (as they are taken during the same month). Therefore, this study does not pretend to establish the causal chain of events that lead to arrest (nor is this the goal).
} 


\section{Results}

Table 2 presents the results of the GLM models. We start with a simple model which begins to test our first research hypothesis on the impact of criminal exposure. In this model, the duration of criminal activity is included as a dynamic factor along with intensity of offending (number of crimes committed). This model tells us how much risk offenders incur as time passes during the window period, controlling for criminal involvement. Results show, as expected, that both duration and intensity of criminal activity are risk factors: each additional month that offenders are active, risks of arrest increase by $4.3 \%$. In addition, each increase in offending frequency is associated with an increase in the probability of being arrested.

These findings hold controlling for a variety of static risk factors also included in model 1. Some of those factors significantly affect risks in ways that we would expect. For example, a history of incarceration emerges as a risk factor, and an earlier age of onset is associated with an increase in risks of arrest. Also, consistent with Gottfredson and Hirschi's (1990) general theory of crime, offenders who have lower self-control also have higher risks of being arrested. Static variables included also highlight the importance of the criminal network. A larger criminal network and the presence of a mentor in crime were associated with lower risks of being arrested. The first model emphasizes both the fatality of the arrest event in our sample, and the importance of individual characteristics to understand probability of being arrested in a given month.

Model 2 introduces three dynamic covariates representing different mechanisms of social (legitimate work and living with an intimate partner) and legal control (being under surveillance) that are expected to be associated with the arrest event. The results suggest that neither living with a partner nor being under surveillance are associated with the timing of arrests. Instead, changes in legitimate work involvement appear to be a significant correlate of arrest. All else 
equal, months in which offenders hold to a legitimate job decrease their likelihood of being arrested. No changes were noted to the static predictors in model 2, with the exception of history of past incarceration and presence of a mentor in crime which were no longer significant after we include social and legal control mechanisms.

[Table 2 about here]

Previous models indicated that the number of crimes committed is associated with an increase in the risks of being arrested. Model 3 now examines whether the mix of crimes committed is important as well. The market crime ratio gives us the proportion of crimes, for a specific month, involving an exchange of illegal goods between consensual parties. Including the market crime ratio in model 3 shows that the crime mix in which offenders are involved is associated with the arrest event: the more offenders specialize in market crimes for a given month, the lower the risks of being arrested. Additionally, the market crime ratio reduces the importance of intensity of criminal activity to non-significance. In short, the mix of crimes matters more than the volume of crimes. The introduction of the market crime ratio also cancels out the effect of static factors such as low self-control and the size of the criminal network. The only static characteristic that remains significant after the inclusion of the market crime ratio is age of onset. In sum, the individual differences between offenders (static factors) matter less when taking into account life circumstances.

Model 4 tests our second hypothesis by introducing an indicator of criminal efficiency. Model 4 shows that those months in which offenders improve their criminal efficiency - that is, months for which they increase their mean pay-off per crime - are associated with lower probabilities of being arrested. Model 4 provides strong support for the use of multi-level model models in which criminal career parameters are allowed to change over time. Dynamic factors such as changes in the mix of crimes committed, or in criminal efficiency, are more salient than 
static factors - including predictors such as past incarceration, or low self-control ${ }^{12}$. In Model 4, the only remaining significant static factor is age of onset, and it is marginally significant.

Could it be that our analytic strategy implicitly favors dynamic factors over static characteristics? And perhaps more importantly, is it only changes in criminal efficiency that matters, or would a static measure of efficiency be just as powerful? In other words, are offenders generally receiving the highest pay-offs per crime also less likely to be arrested? To find out, we created two new static covariates based on two dynamic indicators which were shown to be strongly associated with arrest risks in model 4: 1) criminal efficiency, and 2) involvement in market crime. These two predictors were aggregated as a single measure that captures the full time period for which individuals were criminally active. Both mean criminal efficiency and mean involvement in market crime ratios emerge as significant when introduced as static indicators in model 5. This suggests that both variations in, and, general levels of efficiency and market crime involvement (between-individual differences) are negatively associated with arrest risks. These results signal robust effects for these two characteristics, showing that both static and dynamic factors are important.

\section{Additional Analyses}

Many of the static indicators in our models were not shown to be correlated with arrest risks. These factors may nonetheless be important to the general story, especially in the form of indirect effects. Table 3 presents a series of multi-level regressions using the dynamic factors as dependent variables and our static factors as independent variables.

\section{[Table 3 about here]}

\footnotetext{
12 The effect of low self-control is relatively robust, and only disappears when the dynamic measures for mix of crimes and criminal efficiency are considered. At the bivariate level, low self-control is associated (in the expected direction) with age of onset, hard drug use, daily alcohol use, and presence of a mentor (offenders who reported having had a mentor score significantly higher on the self-control scale).
} 
These analyses can be summarized in four key observations. First, a characteristic that was only marginally associated with arrest risks in table 2 , size of the criminal network, emerged as a significant positive predictor in 3 out of 6 models. Offenders embedded in large criminal networks are more likely to be criminally active for a longer period, to have a higher number of crimes committed, and to be involved in market crimes. While not a strong direct predictor of arrest risks, then, a larger criminal network is associated with many of its main predictors. Second, these analyses also emphasize the indirect effects of education levels. Offenders with at least a high school diploma have a lower intensity of criminal activity than others, but are more likely to engage in market crimes, and to be more efficient in their criminal activities. While conventional human capital has not been shown to be associated with arrest avoidance (Bouchard \& Ouellet, 2011) or criminal earnings (McCarthy \& Hagan, 2001; Morselli \& Tremblay, 2004), here it appears to predict monthly variations in pay-offs per crime. In short, a better education may not directly decrease the probabilities of being arrested, but it increases the likelihood of offenders finding themselves in a position to receive high rewards per crime, which is itself an important predictor of low arrest risks.

Third, while a history of incarceration was not found to be associated with arrest risks, it emerged as significantly associated with not being involved in legitimate work - itself a predictor of lower probabilities of being arrested. In addition, offenders with a history of incarceration are much less likely to be involved in market crimes. Finally, while having a criminal mentor and hard drug use have not been shown to be directly associated with arrest risks, both appear to be associated with criminal efficiency. Hard drug users are much less likely to receive high pay-offs from crimes, which is not unexpected. The significant, positive association between mentor and criminal efficiency is perhaps most interesting. While the number of potential partners in criminal 
networks does not predict criminal efficiency, the presence of a mentor facilitates higher pay-offs per crime, a finding which has also been shown elsewhere (Morselli et al., 2006).

\section{Discussion}

This study started by presenting two hypotheses that capture two opposing views on arrest risks. The exposure hypothesis offers a deterministic view of arrest risks where arrest is a function of the duration and intensity of criminal involvement. The competence hypothesis offers a more active role to offenders who are assumed to vary in their ability to avoid arrest. Surprisingly little prior research has been devoted to this topic. Yet, the theoretical and policy implications underlying the possibility that offenders have differential abilities to avoid detection are numerous. Theories of recidivism and crime persistence have yet to incorporate notions of criminal achievement and competence as predictors, despite the growing set of studies suggesting that 1) a minority, yet influential sub-population of offenders can be found in almost every study sample, incarcerated (Morselli \& Tremblay, 2004; Tremblay \& Morselli, 2000) or otherwise (McCarthy \& Hagan, 2001; Nguyen \& Bouchard, 2013), 2) success is a predictor of persistence in criminal careers (Morselli et al., 2006; Shover \& Thompson, 1992). Successful offenders become mentors to younger offenders (Cloward \& Ohlin, 1960; Morselli et al., 2006; Short \& Strodtbeck, 1965), and act as sources of influence to less successful offenders who have role models to look up to (Tremblay \& Morselli, 2000). The implications for risk assessment tools are clear, yet mostly ignored.

Our findings suggest that these two hypotheses are complementary in understanding risks of arrest. Although it is reasonable to assume that more intense and extended criminal activities are associated with greater risks of detection, our results bring important nuances to that assertion. Recall that exposure, the cumulative effect of time active in crime and intensity of 
criminal activity, has been shown to be a dominant factor in our early models (model 1 and 2). The exposure effect fades when considering monthly variations in offender's skill level in their criminal activities. Degree of specialization in market crimes exceeded the importance of the volume of crimes committed (model 3). Our results add to recent studies that showed that patterns of diversification/specialization are not constant over the criminal career (McGloin et al. 2007; Shover, 1996; Steffensmeier \& Ulmer, 2005), adding that these variations may also have an influence on arrest risks. Several types of crime are available to offenders driven by financial motivations, but some forms of market crimes - especially those providing the highest pay-offs per crime - may not be available to all (e.g. Desroches, 2005; Shover, 1996). Barriers to entry in the form of skills, social capital, and financial resources are often required to thrive and survive in these activities (Bouchard \& Ouellet, 2011; Ouellet et al., 2016). For example, our additional analyses highlighted the importance of the size of core criminal network in predicting the level of involvement in market crimes.

It would be wise for future research to adopt research designs amenable to the analysis of the mix of situational and social factors allowing offenders to take advantage of the very best criminal opportunities available. Some of these opportunities are found within social opportunity structures that remain well guarded and inaccessible to those who lack either the raw skills, or the right connections (Bouchard \& Nguyen, 2011; Kleemans \& de Poot, 2008; Ouellet et al., 2016; Steffensmeier and Ulmer, 2005). The criminal opportunity structures that allow offenders to thrive and pursue "systematic criminal behavior" are rarely described or used as units of analyses in criminological research (Ouellet et al., 2016; Steffensmeier \& Ulmer, 2005; Tremblay, 2010). This relative neglect contrasts with the importance that opportunity structures had taken in the early development of the field, especially as a crucial element of subcultural theories of crime (Cohen, 1955; Cloward \& Ohlin, 1960; Short \& Strodtbeck, 1965; Tremblay, 2010). The 
interplay between individuals and the larger socio-criminal context in which their crimes are embedded is just as important in understanding variations in the careers of persistent criminals as in explaining why offenders embark on criminal careers in the first place.

The notion of efficiency is remarkably absent from the criminal career framework and treated as an aside. But the notion that offenders may have differing abilities when it comes to crime, and when it comes to avoiding arrest has immediate intuitive appeal. Our results indicate that such an idea may very well be a powerful one in determining the risks of being arrested. Months in which offenders were more efficient in terms of earning more money per crime were also months in which their risks of being arrested were low. This finding suggests a link between two objective measures of criminal achievement, risk avoidance and illegal earnings. This finding was also shown to hold true when we removed monthly variations and instead examined the general (static) effect of criminal efficiency. In other words, offenders who generally earn higher pay-offs per crime are less likely to be arrested. Our interpretation of this finding is that a demonstrated efficiency in earning money from crime is indicative of a set of skills, or competence, that facilitates criminal achievement more generally. This is so, we argue, because of the nature of the opportunities conducive to high pay-offs per crime, and the differential access offenders have to these opportunities. These opportunities are typically difficult to unpack for researchers as they generally will not emerge from the level of detail provided in the typical selfreported crime surveys or in official crime data. For example, although high-level drug trafficking may be a type of crime for which pay-offs are relatively high (Bouchard \& Ouellet, 2011; Desroches, 2005), the majority of offenders involved in drug trafficking do not receive atypical revenues from their involvement. The division of profits involved in drug trafficking favors the "organizers" or "managers" of an importation or exportation scheme, as opposed to the majority of participants involved in lesser roles, such as mules and transporters (Decker and 
Chapman, 2008; Desroches, 2005). The distribution of risks follows a similar logic: relatively high for transporters, and relatively low for organizers (Dorn, Oette \& White, 1998), creating a rich get richer phenomenon that some of our findings appear to capture. Yet, all of these individuals would be found in a general category of "drug trafficking" in most datasets (or "drug offenders/offenses"), which would mask the stark differences in success rates among this subcategory of offenders. For these reasons, but also because the minority of successful criminals are a source of inspiration for the majority of less successful ones (Morselli et al., 2006; Tremblay \& Morselli, 2000), we urge criminologists to integrate questions on criminal earnings and pay-offs per crime in their surveys. This is especially crucial in longitudinal studies where variations in arrest risks and criminal earnings can be followed over time, and where causal processes can be tested.

It should be noted that although our analyses show the importance of competence in arrest avoidance, it remains that the duration of criminal activities continues to be a strong predictor of risks. No matter the skills and strategies put forward by our offenders, time was against them. This finding partly reflects the nature of this sample of incarcerated offenders. There is little doubt that our study should be replicated to a sample of active offenders. At the same time, any active offender has a non-zero risk being arrested, and such risk is bound to increase for each additional crime committed (Blumstein et al., 2010). The rate at which risks increase is likely to be over-estimated in our study of incarcerated offenders. Yet, even the most successful offenders are detected at some point in their careers. In our sample, many offenders described long careers with very few, if any, incarceration periods before the ones they were going through at the time of interview. As much as a sample of incarcerated offenders, by its very nature, will contain a mix of failed offenders and a few successful ones, a sample of active offenders would also contain a mix of offenders biased towards specific characteristics. To be sure, the vast majority of 
our offenders were criminally active for a majority of the 36-month window period, making them candidates for sampling designs of "active offenders" as well.

Other limitations of our data and analyses need to be taken into account when interpreting our results. First, it would have been desirable to have even more measures at the dynamic level (e.g. habits of co-offending and alcohol/drug use). Also, we cannot rule out the effect of marital relations since the quality of these are likely to be more meaningful than simply being "in a stable relationship" - as measured in this study. Second, although this study attempts to improve knowledge on criminal competence, we cannot confirm that offenders made conscious use of their skills in order to avoid detection. The association between pay-off per crime and arrest risk may be indirect, and fully explained by an unmeasured characteristic, or the specific criminal circumstances in which offenders committed their offenses. In addition, we cannot rule out the possibility that the window period analyzed was somehow atypical, and that different results might be obtained should we had access to the entire criminal career of these offenders. Relatedly, there is a clear need to improve our measurement of criminal competence. While indepth interviews and ethnographic studies of successful criminals have been able to report on the relative objective skills of various types of offenders (Steffensmeier \& Ulmer, 2005; Sutherland, 1937), the next step for achievement scholars is to find ways to integrate valid measures of skills amenable to larger survey contexts.

In addition, it should be noted that the current study design could only provide a partial examination of the role of competence in avoiding arrest. Implicit in our use of criminal competence to study the risk of being arrested is that offenders who score high on indicators of competence are behaving in ways that decrease these risks for themselves. A growing set of studies have recently drawn from the concept of restrictive deterrence (Gibbs, 1975; Jacobs, 2010) to examine arrest avoidance behaviors among offenders (Beauregard \& Bouchard, 2010; 
Gallupe, Bouchard \& Caulkins, 2011). The current study, however, is unable to measure the specific ways in which offenders may have changed their behavior in order to avoid detection. These arrest avoidance behaviors, including specific innovations in modus operandi to increase criminal benefits (Lacoste \& Tremblay, 2003), are themselves potential indicators of competence that can partially mediate the relationship uncovered in this study. We expect, however, criminal efficiency to retain its strong, direct impact on arrest risks even in more complex models.

Finally, the study does not directly answer an important question: where does competence come from, and can it be altered ${ }^{13}$ ? We believe this question to be an important one for the next generation of criminal achievement studies, but we also believe it to be distinct from the typical question around criminal success. Instead of asking, 'who gets ahead in crime?', this sub-area of achievement studies would ask, 'how does one become a skilled criminal'? This is far from a new question, in fact, there is an 80-year research tradition around these types of inquiries (Sutherland, 1937; Steffensmeier \& Ullmer, 2005), including theoretical and ethnographic investigations of the criminal subcultures in which skilled criminals grew up, and were trained (Cohen, 1955; Cloward \& Ohlin, 1960). For these early subcultural theorists, a key aspect of learning to become a good criminal was to be found in the availability of mentorship from older, successful offenders. The idea that we learn important skills in closed social circles is not unique to crime, but instead can be extended to the skills and abilities used in conventional pursuits (Coleman, 1988). Research programs around the development and impact of criminal competence should also pay attention to life circumstances and turning points in the acquisition of specific skills, including periods of incarceration (see Nguyen et al., 2016) and post release. This program should find a way to capture all dimensions of the concept (e.g. criminal efficiency, sound decision-making), and do so through a variety of approaches, including surveys. Network

\footnotetext{
${ }^{13}$ We thank an anonymous reviewer for suggesting we discuss this issue.
} 
approaches, in particular, may provide a powerful set of theory and methods to understand the mechanisms at play (Kreager, Schaefer, Bouchard, Haynie, Wakefield, Young, \& Zajac, 2015).

\section{Conclusion}

Criminal achievement research generally considers one of the following two dimensions of criminal success: 1) the ability to evade detection (e.g. Bouchard \& Nguyen, 2010); 2) the ability to maximum pay-offs from criminal opportunities, whether it is for money-oriented (Morselli \& Tremblay, 2004; Nguyen \& Bouchard, 2013; Tremblay \& Morselli, 2000), or predatory violent offenses (Lussier, Bouchard, \& Beauregard, 2011). In almost all of these studies, a) a single dimension of achievement is examined, and b) competence is measured only indirectly, or avoided for the related but distinct measures associated with criminal human capital (e.g. criminal experience, specialization. The current study argued that criminal efficiency - an indicator of one dimension of criminal competence - could capture an important characteristic predicting criminal achievement, and that this measure could be informed by the manner with which offenders earn money from crime. We find that the efficiency with which offenders earn money from crime is both a static (high earners are arrested less often) and a dynamic (increases in monthly criminal efficiency are associated with lower arrest rates).

Contextual contingencies are crucial in understanding behavior, criminal or otherwise. The use of multilevel models has allowed examination of the probability of being arrested within criminal careers while controlling for a variety of static and dynamic factors. Our study demonstrates the usefulness of dynamic models. The results emphasize the importance of changes in life circumstances to understand the dynamics of criminal careers. A major finding that emerges from our analysis is that life circumstances are associated with the odds of being arrested within the window period, but also that static individual characteristics show very small effects after changes in context is taken into account. This finding may explain why several 
studies based on a dynamic design did not include offender's characteristics in their models (Griffin \& Armstrong, 2003; Horney et al., 1995; Uggen \& Thompson 2003). However, in the additional analyses carried out on the effects of static factors, we found that the effect of life circumstances is often conditional on the presence of specific individual characteristics. For example, we know that older and more educated offenders are more likely to engage in market crimes, and that involvement in this type of crime is associated with lower risks of arrest. Importantly, our study has not only considered the impact of conventional life circumstances, but also circumstances of a criminal lifestyle. Although studies examining aspects of the criminal careers continue to flourish, the relationships between key dimensions of the criminal career are still relatively unknown. This article shows the importance of these relationships in avoiding arrests. Of note, the influence of lambda (criminal frequency/intensity) is inhibited by the degree of specialization in market crimes, which directly impact the likelihood of being arrested in a given month. Our study argues for the inclusion of criminal achievement in general, and criminal competence in particular, as central dimensions of criminological inquiry. Despite an increase in the attention given to the topic over the past decade, variations in criminal competence and criminal achievement remain under-researched areas for criminologists. This is so despite the importance given to these aspects in a variety of decisions made by offenders, including the decision to start or persist in a career in crime.

\section{References}

Anwar, S., \& Loughran, T. A. (2011). Testing a Bayesian learning theory of deterrence among serious juvenile offenders. Criminology, 49, 667-698.

Beauregard, E., Bouchard, M. (2010). Cleaning up your act: Forensic awareness as a detection avoidance strategy. Journal of Criminal Justice, 38: 1160-1166 
Blumstein, A., Cohen, J., Roth, J. A., \& Visher, C. A. (1986). Criminal careers and « Career

Criminals » (Vol. 1). Washington, D. C.: National Academy Press.

Blumstein, A., Cohen, J., Piquero, A., Visher, C. (2010). Linking the crime and arrest processes to measure variations in individual arrest risk per crime (Q). Journal of Quantitative Criminology, $26: 533-548$.

Bouchard, M., \& Nguyen, H. (2010). Is it who you know, or how many that counts? Criminal networks and cost avoidance in a sample of young offenders. Justice Quarterly, 27, 130158.

Bouchard, M., \& Nguyen, H. (2011). Professionals or amateurs? Revisiting the notion of professional crime in the context of cannabis cultivation. In T. Decorte, G. Potter \& M. Bouchard (Eds.),World Wide Weed: Global Trends in Cannabis Cultivation and its Control (pp. 109-125). London: Ashgate.

Bouchard, M., \& Ouellet, F. (2011). Is small beautiful? The link between risks and size in illegal drug markets. Global Crime, 12(1), 70-86.

Brezina, T., \& Topalli, V. (2012). Criminal self-efficacy exploring the correlates and consequences of a "successful criminal" identity. Criminal Justice and Behavior, 39(8), 1042-1062.

Caulkins, J. P., \& MacCoun, R. (2003). Limited rationality and the limits of supply reduction. Journal of Drug Issues, 33, 433-464.

Charest, M. (2004). Peut-on se fier aux délinquants pour estimer leurs gains criminels? Criminologie, 63-87.

Clausen, J. (1991). Adolescent competence and the shaping of the life course. American Journal of Sociology, 96: 805-842.

Cloward, R. A., \& Ohlin, L. E. (1960). . Delinquency and opportunity. New York: Free Press. 
Cohen, A. K. (1955). Delinquent Boys: The Culture of the Gang. New York: Taylor \& Francis.

Coleman, J. (1988). Social capital in the creation of human capital. American Journal of Sociology, 94: S95-S120.

Decker, S. H., \& Chapman, M. T. (2008). Drug smugglers on drug smuggling. Philadelphia: Temple University Press.

Desroches, F. J. (2005). The Crime that Pays: Drug Trafficking and Organized Crime in Canada. Toronto: Canadian Scholars' Press.

Dorn, N., Oette, L., \& White, S. (1998). Drugs importation and the bifurcation of risk capitalization, cut outs and organized crime. British Journal of Criminology 38, 537-560.

Farrington, D. P., Jolliffe, D., Hawkins, J. D., Catalano, R. F., Hill, K. G., \& Kosterman, R. (2003). Comparing delinquency careers in court records and self-reports. Criminology, 41, 933-958.

Freedman, D., Thornton, A., Camburn, D., Alwin, D., \& Young-DeMarco, L. (1988). The life history calendar: A technique for collecting retrospective data. Sociological Methodology, 18, 37-68.

Gallupe, O., Bouchard, M., \& Caulkins, J. P. (2011). No change is a good change? Restrictive deterrence in illegal drug markets. Journal of Criminal Justice, 39, 81-89.

Gibbs, J. P. (1975). Crime, Punishment, and Deterrence. New York: Elsevier.

Glaser, D. (1969). The Effectiveness of a Prison and Parole System. Indianapolis: Bobb-Merrill.

Gottfredson, M. R. a. H., Travis. (1990). A General Theory of Crime. Stanford: Stanford University Press.

Grasmick, H. G., Tittle, C. R., Bursik, R. J., \& Arneklev, B. J. (1993). Testing the core empirical implications of Gottfredson and Hirschi's general theory of crime. Journal of Research in Crime and Delinquency, 30, 5-29. 
Griffin, M. L., \& Armstrong, G. S. (2003). The effect of local life circumstances on female probationers' offending. Justice Quarterly, 20, 213-239.

Hirschi, T., \& Gottfredson, M. (1983). Age and the explanation of crime. American Journal of Sociology, 89, 552-584.

Horney, J., \& Marshall, I. H. (1991). Measuring lambda through self-reports. Criminology, 29, 471-495.

Horney, J., Osgood, D. W., \& Marshall, I. H. (1995). Criminal careers in the short-term: Intraindividual variability in crime and its relation to local life circumstances. American Sociological Review, 60, 655-673.

Huebner, B. M., Varano, S. P., \& Bynum, T. S. (2007). Gangs, guns, and drugs: recidivism among serious, young offenders. Criminology \& Public Policy, 6, 187-221.

Jacobs, B. A. (2010). Deterrence and deterrability. Criminology, 48, 417-441.

Jacobs, B. A., \& Wright, R. (2006). Street justice: Retaliation in the Criminal Underworld. Cambridge: Cambridge University Press.

Kleemans, E. R., \& de Poot, C. J. (2008). Criminal careers in organized crime and social opportunity structure. European Journal of Criminology, 5, 69-98.

Kreager, D., Schaefer, D., Bouchard, M., Haynie, D., Wakefield, S., Young, J., Zajac, G. (2015). Toward a criminology of inmate networks. Justice Quarterly. Online First.

Lacoste, J., \& Tremblay, P. (2003). Crime and innovation: A script analysis of patterns in check forgery. Crime Prevention Studies, 16, 169-196.

Lattimore, P. K., Visher, C. A., \& Linster, R. L. (1995). Predicting rearrest for violence among serious youthful offenders. Journal of Research in Crime and Delinquency, 32(1), 54-83

Laub, J. H., \& Sampson, R. J. (2003). Shared Beginnings, Divergent Lives: Delinquent Boys to Age Seventy. Cambridge: Harvard University Press. 
Loughran, T. A., Nguyen, H., Piquero, A. R., \& Fagan, J. (2013). The returns to criminal capital. American Sociological Review, 78, 925-948.

Loughran, T. A., Paternoster, R., Piquero, A. R., \& Fagan, J. (2012). “A good man always knows his limitations": The role of overconfidence in criminal offending. Journal of Research in Crime and Delinquency, 50, 327-358.

Lussier, P., Bouchard, M., \& Beauregard, E. (2011). Patterns of criminal achievement in sexual offending: Unravelling the "successful” sex offender. Journal of Criminal Justice, 39, 433444.

Lussier, P., \& Davies, G. (2011). A person-oriented perspective on sexual offenders, offending trajectories, and risk of recidivism: A new challenge for policymakers, risk assessors, and actuarial prediction? Psychology, Public Policy, and Law, 17, 530-561.

Lussier, P. \& Mathesius, J. (2012). Criminal achievement, career initiation, and cost avoidance: The onset of successful sex offending. Journal of Crime and Justice, 35, 376394.McCarthy, B., \& Hagan, J. (2001). When crime pays: Capital, competence, and criminal success. Social Forces, 79, 1035-1060.

McCarthy, B., \& Hagan, J. (2001). When crime pays: Capital, competence, and criminal success. Social forces, 79, 1035-1060.

McGloin, J. M., Sullivan, C. J., Piquero, A. R., \& Pratt, T. C. (2007). Local life circumstances and offending specialization/versatility comparing opportunity and propensity models. Journal of Research in Crime and Delinquency, 44, 321-346.

Morris, N. A., \& Slocum, L. A. (2010). The validity of self-reported prevalence, frequency, and timing of arrest: An evaluation of data collected using a life event calendar. Journal of Research in Crime and Delinquency, 47, 210-240. 
Morselli, C., \& Tremblay, P. (2004). Criminal achievement, offender networks and the benefits of low self-control. Criminology, 42, 773-804.

Morselli, C., Tremblay, P., \& McCarthy, B. (2006). Mentors and criminal achievement. Criminology, 44, 17-43.

Morselli, C., \& Tremblay, P. (2010). Interviewing and validity issues in self-report research with incarcerated offenders: the Quebec inmate survey. In W. Bernasco (Ed.). Portland, OR: Willan Publishing.

Nagin, D. S. (1998). Criminal deterrence research at the outset of the twenty-first century. Crime and Justice, 1-42.

Nagin, D. S., \& Land, K. C. (1993). Age, criminal careers, and population heterogeneity: specification and estimation of a nonparametric, mixed Poisson model. Criminology, 31, 327-362.

Nguyen, H., \& Bouchard, M. (2013). Need, connections, or competence? Criminal achievement among adolescent offenders. Justice Quarterly, 30, 44-83.

Nguyen, H., Loughran, T. A., Paternoster, R., Fagan, J., \& Piquero, A. R. (2016). Institutional Placement and Illegal Earnings: Examining the Crime School Hypothesis. Journal of Quantitative Criminology, 1-29.

Ouellet, F., Boivin, R., Leclerc, C., \& Morselli, C. (2013). Friends with (out) benefits: cooffending and re-arrest. Global Crime, 14, 141-154.

Ouellet, M., Bouchard, M., Malm, A. (2016). Social opportunity structures and the escalation of drug market offending. Journal of Research in Crime and Delinquency. Online First.

Paternoster, R., \& Piquero, A. (1995). Reconceptualizing deterrence: An empirical test of personal and vicarious experiences. Journal of Research in Crime and Delinquency, 32, 251-286. 
Piliavin, I., Gartner, R., Thornton, C., \& Matsueda, R. L. (1986). Crime, deterrence, and rational choice. American Sociological Review, 101-119.

Piquero, A. R. (2004). Somewhere between persistence and desistance: The intermittency of criminal careers. In S. Maruna \& R. Immarigeon (Eds.), After Crime and Punishment: Pathways to Offender Reintegration (pp. 102-125). Portland, OR: Willan Publishing.

Piquero, A. R., Blumstein, A., Brame, R., Haapanen, R., Mulvey, E. P., \& Nagin, D. S. (2001). Assessing the impact of exposure time and incapacitation on longitudinal trajectories of criminal offending. Journal of Adolescent Research, 16, 54-74.

Piquero, A. R., Paternoster, R., Pogarsky, G., \& Loughran, T. (2011). Elaborating the individual difference component in deterrence theory. Annual Review of Law and Social Science, 7, $335-360$.

Roberts, J., Mulvey, E. P., Horney, J., Lewis, J., \& Arter, M. L. (2005). A test of two methods of recall for violent events. Journal of Quantitative Criminology, 21, 175-193.

Saltzman, L., Paternoster, R., Waldo, G. P., \& Chiricos, T. G. (1982). Deterrent and experiential effects: The problem of causal order in perceptual deterrence research. Journal of Research in Crime and Delinquency, 19, 172-189.

Short, J. F., \& Strodtbeck, F. L. (1965). Group Process and Gang Delinquency. Chicago: University of Chicago Press.

Shover, N. (1996). Great Pretenders: Pursuits and Careers of Persistent Thieves. Boulder: Westview Press Boulder.

Shover, N., \& Thompson, C. Y. (1992). Age, differential expectations, and crime desistance. Criminology, 30, 89-104.

Stafford, Warr, M. (1993). A reconceptualization of general and specific deterrence. Journal of Research in Crime and Delinquency, 30:123-135. 
Steffensmeier, D. J., \& Ulmer, J. T. (2005). Confessions of a Dying Thief: Understanding

Criminal Careers and Illegal Enterprise. Somerset: Aldine transaction

Sutherland, E. H. (1937). The Professional Thief. By a Professional Thief. Annotated and

Interpreted by Edwin H. Sutherland. Chicago: University of Chicago Press.

Sutton, J. E., Bellair, P. E., Kowalski, B. R., Light, R., \& Hutcherson, D. T. (2011). Reliability and validity of prisoner self-reports gathered using the life event calendar method. Journal of Quantitative Criminology, 27, 151-171.

Tremblay, P. (1993) Searching for suitable co-offenders. In R. V. Clarke, and M. Felson, Routine Activity and Rational Choice: Advances in Criminological Theory (pp. 17-36). New Brunswick, NJ: Transaction.

Tremblay, P. (2010). Le délinquant Idéal. Performance, Discipline, Solidarité. Montréal, Liber. Tremblay, P., \& Morselli, C. (2000). Patterns in criminal achievement: Wilson and Abrahamse revisited. Criminology, 38, 633-657.

Uggen, C., \& Thompson, M. (2003). The Socioeconomic Determinants of Ill-Gotten Gains: Within-Person Changes in Drug Use and Illegal Earnings 1. American Journal of Sociology, $109,146-185$.

Van Der Leeden, R. (1998). Multilevel analysis of repeated measures data. Quality and Quantity, $32,15-29$.

Wiesner, M., Capaldi, D. M., \& Kim, H. K. (2007). Arrest trajectories across a 17-year span for young men: relation to dual taxonomies and self-reported offense trajectories. Criminology, 45, 835-863.

Wright, R. T., \& Decker, S. H. (1994). Burglars on the job: Streetlife and residential break-ins. New England: Northeastern University Press. 
Wright, R. T., \& Decker, S. H. (1997). Armed Robbers in Action: Stickups and Street Culture. New England: Northeastern University Press.

Wright, R., Logie, R. H., \& Decker, S. H. (1995). Criminal expertise and offender decision making: An experimental study of the target selection process in residential burglary. Journal of Research in Crime and Delinquency, 32, 39-53. 
Table 1: Descriptive statistics of dynamic and static factors.

\section{Mean (SD)}

Arrest $(1=$ yes; $0=$ no $)$

\section{Level 1: dynamic predictors}

Duration of criminal activity (month number in the sequence)

Intensity of criminal activity ${ }^{a}$ (number of crime committed)

Living with a intimate partner $(1=\mathrm{yes} ; 0=$ no $)$

Legitimate work (1 =yes; $0=$ no)

Surveillance ( $1=\mathrm{yes} ; 0=$ no)

Involvement in market crime (Number of market crime/ number of all crime)

Criminal efficiency ${ }^{\mathrm{a}}$ (earnings per crime)

\section{$\underline{\text { Level } 2 \text { : Static predictors }}$}

Age (at beginning of window period)

High school diploma (1= graduated; $0=$ did not graduate)

Age at onset (age at first crime)

Low Self Control score (sum of the 24 items on the Grasmick's scale)

Daily use of alcohol ( $1=$ yes; $0=$ no $)$

Hard drugs use ( $1=$ yes; $0=$ no $)$

Past incarceration (number of past incarceration)

Size of core criminal network (number of offenders in the criminal networks)

Presence of a mentor in crime ( $1=\mathrm{yes} ; 0=\mathrm{no})$
$.08(.28)$

\% of sample with change in

$\underline{\text { status }(2+\text { more transitions })}$

$$
13.80(9.60)
$$

$30.59(10.87)$

$.55(.28)$

$.43(.50)$

$.34(.02)$

$.41(.49)$

$.41(.14)$

$.20(.40)$

$.28(.02)$

$68.94(43.31)$

$.44(.15)$

$245.28 \$(16.44)$

$.71(.41)$
$32.37(8.51)$

$.19(.39)$

$15.20(6.81)$

$80.28(14.47)$

$.28(.45)$

$.58(.50)$

$1.79(1.52)$

$6.92(3.00)$

$.42(.50)$ 
Table 2: Life circumstances and characteristics of offenders on monthly risks of arrest: Generalized linear mixed (GLM), logistic coefficients $(\gamma)$ and Odds Ratio.

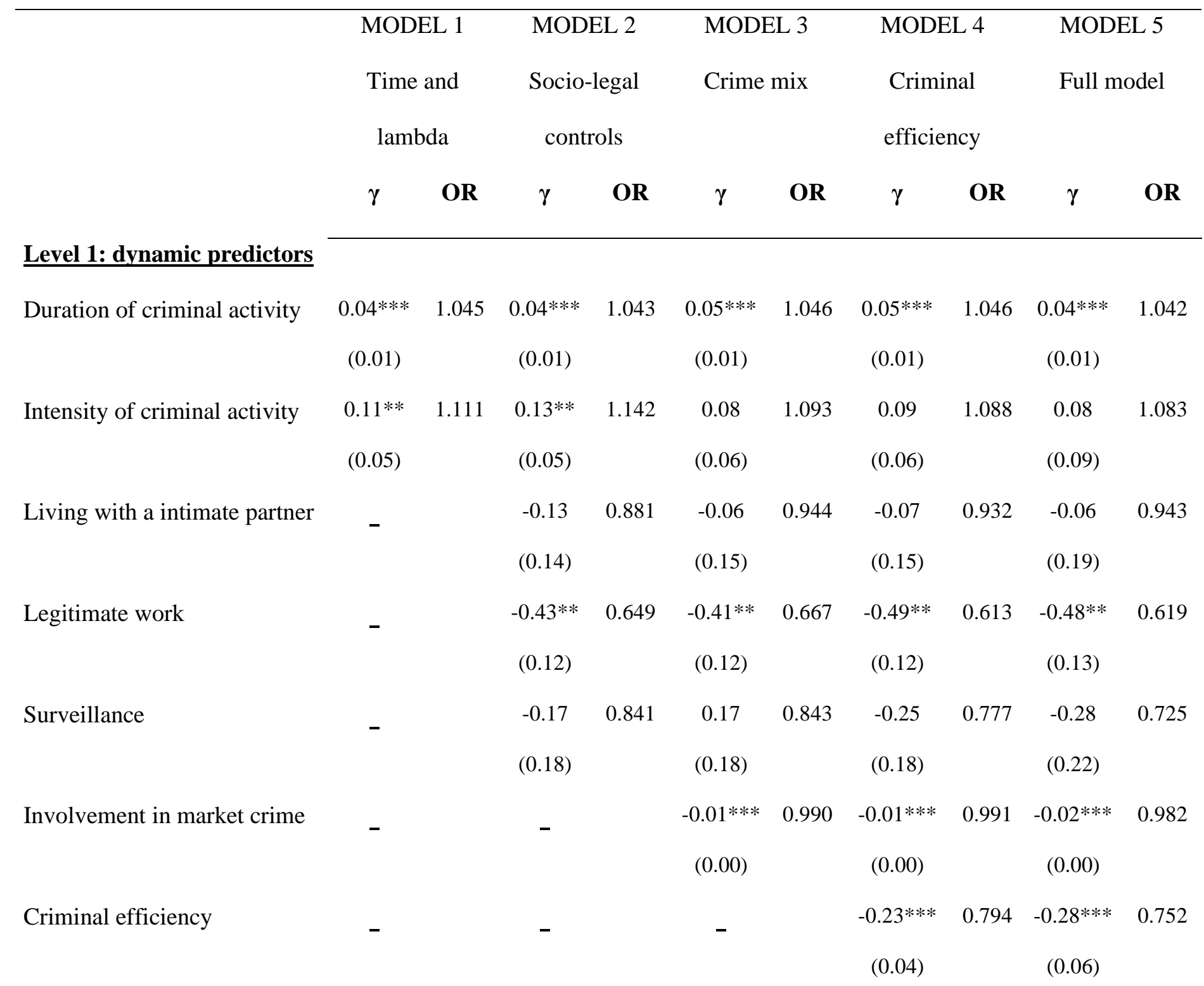

\section{Level 2 : Static predictors}

$\begin{array}{lcccccccccc}\text { Age } & -0.00 & 0.997 & -0.00 & 0.996 & 0.01 & 1.006 & 0.01 & 1.006 & 0.00 & 1.001 \\ & (0.01) & & (0.01) & & (0.01) & & (0.01) & & (0.01) & \\ \text { High school diploma } & -0.24 & 0.784 & -0.24 & 0.787 & -0.27 & 0.763 & -0.13 & 0.882 & -0.11 & 0.863 \\ & (0.19) & & (0.20) & & (0.22) & & (0.21) & & (0.24)\end{array}$




\begin{tabular}{|c|c|c|c|c|c|c|c|c|c|c|}
\hline Age at onset & $\begin{array}{r}-0.03^{*} \\
(0.02)\end{array}$ & 0.967 & $\begin{array}{c}-0.03 * \\
(0.01)\end{array}$ & 0.970 & $\begin{array}{c}-0.03 * \\
(0.02)\end{array}$ & 0.972 & $\begin{array}{c}-0.03 * \\
(0.02)\end{array}$ & 0.968 & $\begin{array}{l}-0.03 * \\
(0.02)\end{array}$ & 0.968 \\
\hline Low Self Control score & $\begin{array}{l}0.02 * \\
(0.01)\end{array}$ & 1.015 & $\begin{array}{l}0.02 * \\
(0.01)\end{array}$ & 1.015 & $\begin{array}{c}0.01 \\
(0.00)\end{array}$ & 1.011 & $\begin{array}{c}0.01 \\
(0.00)\end{array}$ & 1.011 & $\begin{array}{c}0.01 \\
(0.00)\end{array}$ & 1.009 \\
\hline Daily use of alcohol & $\begin{array}{l}-0.30 \\
(0.19)\end{array}$ & 0.740 & $\begin{array}{l}-0.31 \\
(0.19)\end{array}$ & 0.736 & $\begin{array}{l}-0.23 \\
(0.20)\end{array}$ & 0.794 & $\begin{array}{l}-0.10 \\
(0.19)\end{array}$ & 0.902 & $\begin{array}{l}-0.17 \\
(0.18)\end{array}$ & 0.840 \\
\hline Hard drugs use & $\begin{array}{c}0.18 \\
(0.18)\end{array}$ & 1.202 & $\begin{array}{c}0.16 \\
(0.17)\end{array}$ & 1.178 & $\begin{array}{c}0.02 \\
(0.17)\end{array}$ & 0.995 & $\begin{array}{l}-0.12 \\
(0.17)\end{array}$ & 0.884 & $\begin{array}{c}0.05 \\
(0.18)\end{array}$ & 1.022 \\
\hline Past incarceration & $\begin{array}{l}0.14^{*} \\
(0.07)\end{array}$ & 1.150 & $\begin{array}{c}0.12 \\
(0.07)\end{array}$ & 1.132 & $\begin{array}{c}0.10 \\
(0.07)\end{array}$ & 1.100 & $\begin{array}{c}0.09 \\
(0.07)\end{array}$ & 1.093 & $\begin{array}{c}0.13 \\
(0.08)\end{array}$ & 1.138 \\
\hline Size of core criminal network & $\begin{array}{l}-0.17 * \\
(0.08)\end{array}$ & 0.844 & $\begin{array}{l}-0.16^{*} \\
(0.01)\end{array}$ & 0.854 & $\begin{array}{l}-0.11 \\
(0.08)\end{array}$ & 0.898 & $\begin{array}{l}-0.11 \\
(0.07)\end{array}$ & 0.895 & $\begin{array}{l}-0.10 \\
(0.07)\end{array}$ & 0.899 \\
\hline Presence of a mentor in crime & $\begin{array}{l}-0.34 * \\
(0.17)\end{array}$ & 0.712 & $\begin{array}{l}-0.30 \\
(0.17)\end{array}$ & 0.740 & $\begin{array}{l}-0.19 \\
(0.17)\end{array}$ & 0.823 & $\begin{array}{l}-0.10 \\
(0.17)\end{array}$ & 0.903 & $\begin{array}{l}-0.19 \\
(0.18)\end{array}$ & 0.905 \\
\hline Mean of criminal efficiency & - & & - & & - & & - & & $\begin{array}{l}-0.19 * \\
(0.08)\end{array}$ & 0.826 \\
\hline $\begin{array}{l}\text { Mean of involvement in } \\
\text { market crime }\end{array}$ & - & & - & & - & & - & & $\begin{array}{l}-0.01 * \\
(0.01)\end{array}$ & 0.988 \\
\hline
\end{tabular}

$*=\mathrm{p}<.05 ; * *=\mathrm{p}<.01 ; * * *=\mathrm{p}<.001$ (standard errors are in parentheses) 
Table 3: Interrelations between life circumstances and offender characteristics: non-standardized regression coefficients (b)

\begin{tabular}{|c|c|c|c|c|c|c|c|}
\hline & $\begin{array}{c}\text { Duration of } \\
\text { criminal } \\
\text { activity }\end{array}$ & $\begin{array}{l}\text { Intensity of } \\
\text { criminal } \\
\text { activity }\end{array}$ & $\begin{array}{l}\text { Living with } \\
\text { a intimate } \\
\text { partner }\end{array}$ & $\begin{array}{c}\text { Legitimate } \\
\text { work }\end{array}$ & Surveillance & $\begin{array}{c}\text { Involvement } \\
\text { in market } \\
\text { crime }\end{array}$ & $\begin{array}{l}\text { Criminal } \\
\text { efficiency }\end{array}$ \\
\hline Age & n.s. & n.s. & n.s. & n.s. & $\begin{array}{l}-0.11 * * \\
(0.04)\end{array}$ & $\begin{array}{l}0.99 * \\
(0.42)\end{array}$ & n.s \\
\hline $\begin{array}{l}\text { High school } \\
\text { diploma }\end{array}$ & n.s. & $\begin{array}{l}-1.11 * * \\
(0.38)\end{array}$ & n.s. & n.s. & n.s. & $\begin{array}{l}6.03 * \\
(2.72)\end{array}$ & $\begin{array}{l}1.45^{* *} \\
(0.47)\end{array}$ \\
\hline Age at onset & n.s. & n.s. & n.s. & n.s. & n.s. & n.s & n.s \\
\hline Low Self Control & n.s. & $\begin{array}{l}0.03^{*} \\
(0.01)\end{array}$ & n.s. & n.s. & n.s. & n.s & n.s \\
\hline Daily use of alcohol & n.s. & n.s. & n.s. & n.s. & n.s. & n.s & n.s \\
\hline Hard drugs use & n.s. & $\begin{array}{l}0.76^{*} \\
(0.37)\end{array}$ & n.s. & n.s. & n.s. & n.s & $\begin{array}{l}-1.01 * \\
(0.42)\end{array}$ \\
\hline Past incarceration & n.s. & n.s. & n.s. & $\begin{array}{l}-0.37 * \\
(0.19)\end{array}$ & $\begin{array}{c}0.84 * * * \\
(0.22)\end{array}$ & $\begin{array}{l}-4.30^{*} \\
(2.21)\end{array}$ & n.s \\
\hline $\begin{array}{l}\text { Size of core } \\
\text { criminal network }\end{array}$ & $\begin{array}{l}1.24 * * \\
(0.38)\end{array}$ & $\begin{array}{c}0.54 * * * \\
(0.15)\end{array}$ & n.s. & n.s. & n.s. & $\begin{array}{c}7.22 * * * \\
(2.84)\end{array}$ & n.s \\
\hline $\begin{array}{l}\text { Presence of a } \\
\text { mentor in crime }\end{array}$ & n.s. & n.s. & n.s. & n.s. & n.s. & n.s & $\begin{array}{l}0.93 * \\
(0.41)\end{array}$ \\
\hline
\end{tabular}

